\title{
Economia do Entretenimento: o processo de monopolização do primeiro empreendimento esportivo no Brasil (1850-1930)
}

\author{
João Manuel Casquinha Malaia Santos \\ Professor da Universidade Nove de Julho - SP. \\ E-mail: jmalaia@gmail.com
}

Recebido em 20 de agosto de 2015. Aceito em 25 de setembro de 2015.

\section{RESUMO}

Neste trabalho, analisa-se a organização da produção das corridas de cavalo, o turfe, no Rio de Janeiro, entre 1850 e 1930. O objetivo deste trabalho é compreender como se deu o processo de monopolização da produção de corridas de cavalo no Rio de Janeiro como parte de um processo de acumulação e reprodução capitalista (MARX,1867/1974). Trata-se de uma pesquisa histórica descritiva para identificar as características deste fenômeno em particular que se utiliza de fontes documentais, dados econômicos e censos populacionais. Os resultados mostram o quanto este esporte foi influenciado e influenciou na dinamização da economia capitalista do país, quando após a fase de concorrência e de concentração de capital, ocorreu a monopolização da produção de corridas de cavalo no Rio de Janeiro por apenas uma instituição.

\section{Palavras-chave}

Entretenimento; monopolização; história do esporte

\begin{abstract}
In this paper, the organization of horse racing production (turf) between 1850 and 1930 is analyzed for understanding how was the monopolization proccess of this activity. This proccess is part of the accumulation and reproduction of the capitalist system (MARX, 1867/1974). It is a descriptive historical research to identify particulat characteristics of this phenomenon. The data collected came from documentary sources, economical data, Brazilian press and population census. The results show how this sport was influenced and influence the dynamics of the Brazilian capitalist economy, when after the competition phase and capital concentration, the monopolization of the horce racing production took place in Rio de Janeiro.
\end{abstract}

Keywords

Entertainment; monopolization; sports history 


\section{Introdução}

Nosso público é de sportsmen por natureza, adora as corridas, pouco se importando com o calor. Há corridas? Pois se há, lá vai ele por ahi afora zombando da chuva e rindo-se do sol, lá vai ele encher o prado e no enthusiasmo da corrida, na febre e no delírio de uma chegada emocionante, ele esquece que o sol lhe caustica o rosto, ou que a chuva lhe prepara uma pneumonia. A Capital. Derby Club: Grande Prêmio Progresso. $1^{\circ}$ de janeiro de 1892, p. 2.

O fim do tráfico negreiro, a expansão da lavoura cafeeira na região Sudeste do país e a chegada das primeiras indústrias, trouxeram a ativação de diversos setores da economia nacional a partir da segunda metade do século XIX. Um dos setores que se desenvolveu nas principais cidades do país foi o de entretenimento. A par de teatros, museus e exposições, uma novidade logo passou a ser um dos principais eventos de entretenimento nas grandes cidades do Brasil, a par do que já acontecia em outros locais do mundo como Europa e EUA: as corridas de cavalos. Rapidamente as corridas de cavalo se transformaram em grandes negócios, levando enormes quantidades de pessoas a pagar ingressos para assistir e para fazer apostas. Mas como se deu a organização do primeiro empreendimento esportivo, no Brasil?

Neste trabalho, analisa-se a organização da produção das corridas de cavalo no Rio de Janeiro e seu consumo, mais especificamente na passagem do século XIX para o XX. O objetivo deste trabalho é compreender como se deu o processo de monopolização da produção de corridas de cavalo no Rio de Janeiro. O turfe, como é conhecido o esporte de corridas de cavalo, será observado como um campo organizacional de entretenimento (DI MAGGIO e POWELL, 1983). A ideia é colaborar para a compreensão do processo histórico de formação de organizações dedicadas à produção de eventos esportivos, especificamente de turfe, no Brasil.

Para entendermos melhor o início da produção de uma oferta de eventos esportivos, é preciso observar as condições sociais e econômicas que tornaram possível a construção de um sistema de instituições e agentes direta ou indiretamente relacionados com a existência das atividades de entretenimento esportivo (BOURDIEAU, 1993, p. 58). Desta maneira, poderemos compreender não só como se deu a produção dos eventos, mas também identificar como determinados agentes sociais e organizações estavam envolvidas nesta produção.

As corridas de cavalo foram analisadas como parte de um processo de acumulação e reprodução capitalista (MARX,1867/1974). Após uma expansão dos clubes de corrida na cidade, abrindo uma fase de concorrência, podemos observar um lento processo de concentração de capital em poucos clubes. Ao final do período aqui analisado, a produção de corridas era realizada apenas por um clube, em processo típico de constituição de monopólios (SWEEZY, 1986).

Trabalhamos com um número de fontes de origens variadas, buscando trazer olhares de diferentes grupos a respeito do fenômeno aqui estudado. Os dados econômicos, muitas vezes, têm origem em notas do Diário Oficial e da grande imprensa, bem como nos escritos dos memorialistas deste esporte devido à falta de acesso a fontes 
originais dos clubes de corridas. Apesar de este ser um estudo que pode ser classificado como descritivo, o trabalho pode nos ajudar a levantar questões importantes sobre o desenvolvimento do capitalismo e do campo esportivo no Brasil. Os resultados mostram o quanto este esporte foi influenciado e influenciou na dinamização da economia capitalista do país, quando após a fase de concorrência e de concentração de capital, ocorreu a monopolização da produção de corridas de cavalo no Rio de Janeiro por apenas uma instituição.

Após esta introdução, apresentamos uma breve exposição dos conceitos que ajudam a compreender a organização e o consumo de corridas de cavalo dentro da lógica capitalista. Na sequência são apresentados os procedimentos metodológicos da presente investigação. Após esta parte, apresentam-se mais duas partes em que se explica a organização das corridas de cavalo como espetáculos comercializáveis e como se deu o processo de monopolização das corridas de turfe no Rio de Janeiro. Terminamos esta breve exposição apresentando as considerações finais da observação do turfe carioca como agente da dinâmica capitalista do país.

\section{A organização econômica do turfe}

O Brasil e o Rio de Janeiro passaram por grandes mudanças econômicas a partir da segunda metade do século XIX. Este foi um período marcado "pelos primeiros passos no sentido da 'modernização' do país” (PRADO JUNIOR, 1963, p. 86). As corridas de cavalo podem ser vistas como um dos expoentes desta modernização, tanto nos seus aspectos econômicos, quanto nos aspectos culturais (MELO, 2001). A ideia deste trabalho é entender como se deu a organização da produção de corridas de turfe no Rio de Janeiro. Para tal, é necessário observar esta atividade dentro de um processo mais amplo de desenvolvimento do capitalismo no Brasil. Torna-se importante identificar os diversos agentes e as diversas organizações que estavam direta ou indiretamente envolvidas na realização das corridas, bem como compreender como se dava o consumo deste espetáculo no período em análise.

Torna-se necessário compreender as condições históricas que possibilitaram a formação de um conjunto de agentes sociais que se envolveram com a organização e comercialização de corridas de cavalo no Rio de Janeiro na segunda metade do XIX e primeiras décadas do XX. Diferentemente de países como os EUA, em que a $2^{\mathrm{a}}$ Revolução Industrial trouxe queda nas horas de trabalho por dia, maiores salários e rápida urbanização das cidades (BAKKER, 2003, p. 580), o Brasil ainda vivia em uma economia majoritariamente agrária. Os eventos de corridas de cavalo atraíam a atenção de elementos das mais variadas classes sociais. Tornaram-se importantes espaços sociais, local de convivência de políticos de relevância. Mas tornaram-se também importantes espaços econômicos.

São poucos os trabalhos que procuram entender o passado dos aspectos econômicos deste esporte. Vamplew (1976) foi dos primeiros historiadores do esporte a fazer uma análise mais profunda dos aspectos econômicos do turfe. As mudanças que levaram o esporte a se transformar em um negócio na Inglaterra dos finais do século XIX foram analisadas por Bryant (1986) e Vamplew (1996). Procuramos observar as 
organizações operando em um contexto cultural, político e econômico amplo, caracterizado por relações assimétricas de poder que foram historicamente constituídas (FRISBY, 2012, p. 1).

Primeiramente, precisamos entender o turfe brasileiro como um campo social, um espaço multidimensional de posições formado por diversos atores com papéis mais ou menos relevantes dentro deste campo (BOURDIEU, 1985, p. 724). Tal concepção nos ajuda a identificar quem são os atores e quais são as organizações que de alguma forma ocupavam espaço no campo por nós estudado. Entendemos que todos os atores relevantes do campo têm em comum o interesse em todos os assuntos que dizem respeito à própria existência do campo (BOURDIEU, 1984, p. 121). Portanto, é necessário questionar qual a relevância de cada um dos atores para a existência do campo, ou até mesmo que tipo de disputas de poder são estabelecidas para que se ocupem posições mais ou menos relevantes no campo.

Di Maggio e Powell (1983, p. 148) desenvolveram o conceito de campo organizacional, formado por fornecedores-chave, por consumidores de recursos e de produtos, por agências regulatórias e por outras organizações que produzem os mesmos serviços ou produtos, os competidores. Uma das principais virtudes desta vertente de análise é que ela dirige sua atenção para a totalidade dos atores relevantes envolvidos no processo. O’Brien e Slack (2003, p. 419) usaram este conceito na investigação da profissionalização do rúgbi na Inglaterra, afirmando que todas as organizações esportivas estão embutidas em campos organizacionais. Portanto, estão sujeitas a pressões por parte dos fornecedores-chave, dos consumidores de produtos e de recursos, das agências regulatórias e dos competidores.

Adotando como base o conceito de Di Maggio e Powell (1983) tomamos o turfe brasileiro como campo organizacional. Os clubes de corrida eram ao mesmo tempo fornecedores-chave (por viabilizarem a estrutura para as corridas), competidores do campo organizacional (cada clube oferecendo sua corrida para os criadores) e agências regulatórias do campo (determinavam o funcionamento interno de suas organizações). Os criadores de cavalos também podem ser considerados fornecedores-chave do campo, (por fornecerem os animais para as corridas) e consumidores de recursos (por disputarem os prêmios oferecidos pelos clubes nas corridas). São também consumidores de recursos todos aqueles que trabalham para a produção das corridas, como os cavaleiros, ou jóqueis, os bilheteiros, os seguranças, entre outros. Os consumidores do produto são os espectadores (pagam para ver as corridas), os apostadores e todos aqueles que consomem o turfe, como empresas que utilizam o turfe para publicidade, ou que patrocinam corridas. Vale lembrar que o Estado, ao oferecer benesses a determinados clubes e ao legislar sobre as diversas organizações que se dedicavam ao entretenimento, também deve ser analisado como agência regulatória do campo.

As corridas de cavalo foram analisadas neste trabalho como parte de um processo de acumulação e reprodução capitalista ampliado em seu aspecto mais genérico (MARX,1867/1974). As atividades dos empreendedores dos clubes de corridas foram vistas dentro da lógica de investimentos em capital constante (em estádios) e variável (em cavalos/mão-de-obra, funcionários dos clubes e cavaleiros), de produção e de comercialização de corridas e apostas, e de atividades de monopólio. Após uma 
expansão dos clubes de corrida na cidade, abrindo uma fase de concorrência, podemos observar um lento processo de concentração de capital em poucos clubes. Ao final do período aqui analisado, a produção de corridas era realizada apenas por um clube, em processo típico de constituição de monopólios (SWEEZY, 1986).

Procuramos situar historicamente o consumo de corridas de cavalo como um dos aspectos da consolidação do próprio fenômeno do consumo que toma bases permanentes no mundo a partir do século XIX (McCRACKEN, 2003). Hardy (1986) sugere que os estudos sobre a indústria do esporte em seus aspectos econômicos devem se basear em três tópicos principais: a produção do esporte, o papel dos investidores e administradores de clubes e de ligas e os tipos de organizações e redes criadas por esses personagens para administrar o negócio. Seguindo a sugestão deste autor, analisaremos primeiramente como se dava a produção das corridas de cavalo, qual era o papel daqueles que administravam e investiam em corridas, além de entendermos as organizações que produziam as corridas (os clubes), bem como as redes criadas pelos gestores e investidores dos clubes no sentido de obterem vantagem competitiva no mercado.

Para uma análise dos aspectos econômicos do desenvolvimento do turfe no Rio de Janeiro, ou em qualquer outra localidade em que se institucionalizaram tais eventos de corridas, é primordial estar atento aos diversos agentes envolvidos no empreendimento e no consumo desta atividade. São muitos os envolvidos: os dirigentes dos clubes de turfe, pessoas ligadas ao Estado, trabalhadores envolvidos (bilheteiros, seguranças, tratadores de cavalos, zeladores dos estádios e das pistas, jóqueis) os espectadores e apostadores, aqueles que escreviam na imprensa sobre esta atividade ou os que se valiam do turfe para a confecção de peças publicitárias dos mais variados tipos de produtos.

Além disso, devem ser levados em conta aspectos cruciais na organização de eventos, como a localização dos clubes de turfe e as iniciativas para atração de grandes audiências nas corridas, como as promoções com meios de transporte e os grandes prêmios concedidos aos vencedores das apostas e aos criadores dos cavalos. Tais elementos poderão nos mostrar o quanto a atividade do turfe esteve imbricada com o próprio desenvolvimento do capitalismo no Brasil. Foi ao mesmo tempo agente da transformação e transformador das engrenagens da modernidade e da economia capitalista em transformação na capital do país.

A organização da produção das corridas de turfe tem algumas características peculiares. Na maioria dos esportes, diferentes clubes disputam entre si os eventos esportivos (NEALE, 1964). No caso do turfe, um único clube conseguia produzir sozinho um espetáculo de corridas. O clube deveria fornecer a pista fechada, a estrutura de arquibancadas e de venda de ingressos, a organização de apostas, a segurança no recinto. Os criadores de cavalos contratavam jóqueis, inscreviam seus cavalos nas corridas e disputavam prêmios em dinheiro pagos pelos organizadores, s clubes de corridas. Os animais não corriam representando um clube, mas seus proprietários.

Como não havia disputa nas pistas de um clube contra o outro, não havia a necessidade de formação de ligas, como aconteceu com outros esportes (NEALE, 1964; SLOANE, 1971) no Brasil e no mundo (SANTOS, 2012). No caso do turfe, quanto 
mais e melhores corridas um clube tivesse, maior era sua chance de atrair mais público em detrimento de outros clubes. Desta maneira, o processo de monopolização da produção e do mercado para as corridas de cavalos acontecia na disputa concorrencial de clube para clube. No caso do Rio de Janeiro, apenas um clube sobreviveu, o Jockey Club, vencendo a concorrência e fazendo fusões. O Jockey Club monopolizou a produção de corridas se utilizando das práticas comuns da economia capitalista.

Booth e Rowlison (2006, p. 9) afirmam que as investigações históricas em estudos organizacionais necessitam de uma detalhada justificativa metodológica. Isto serve para as pesquisas em ciências sociais no geral, mas principalmente para pesquisadores qualitativos em estudos organizacionais. Na seção seguinte, apontaremos as questões de metodologia pertinentes à execução deste trabalho.

\section{Metodologia}

A pesquisa histórica fornece subsídios para a compreensão dos significados culturais, das influências históricas e das dinâmicas sociais que moldaram as experiências dos consumidores e suas identidades (ARNOULD e THOMPSON, 2005, p. 601). Muitos autores defendem que a compreensão da gestão do esporte se beneficiaria muito abordando questões de seu passado (ZEIGLER, 1992; BOUCHER, 1998; CHELLADIRA, 1992; OLAFSON, 1995; PATON, 1997). No entanto, são poucos os estudos sobre gestão do esporte no Brasil que procuram se utilizar dos procedimentos metodológicos da história.

Trata-se de uma pesquisa histórica descritiva que tem como função principal identificar as características deste fenômeno em particular (VEAL e DARCY, 2014, p. 141). A pesquisa sobre o turfe brasileiro foi realizada através de métodos qualitativos. Segundo Maanen (1979), apesar da imprecisão do termo, os métodos qualitativos funcionam como uma espécie de guarda-chuva cobrindo um leque de técnicas interpretativas que procuram descrever, decodificar, traduzir e algumas vezes chegar ao significado de certos fenômenos que acontecem com maior ou menor regularidade na sociedade. Tal procedimento, apesar de não poder chegar à frequência com que os eventos ocorrem, procura reduzir a distância entre a teoria e os dados, entre o contexto e a ação. Por conta disso, a descrição torna-se ato fundamental no processo de análise de nosso fenômeno.

Os procedimentos metodológicos da pesquisa histórica apontam para a necessidade de um uso variado de fontes, que devem ser levantadas de acordo com o problema e as perguntas de pesquisa (ARÓSTEGUI, 2006). O único pré-requisito para selecionar os procedimentos de pesquisa é que os mesmos consigam relacionar os dados com a pergunta de pesquisa de um modo que permita o desenvolvimento da interpretação (SMITH e LUX, 1993, p. 601). As fontes utilizadas foram de diferentes naturezas, a fim de conseguir dar uma descrição satisfatória do fenômeno em análise. Foram utilizadas fontes documentais, dados econômicos e censos populacionais.

Por se tratar de uma pesquisa histórica, torna-se necessário um cuidado com os procedimentos metodológicos deste campo do conhecimento. Pontos importantes como o estabelecimento do recorte temporal a ser analisado, o uso de fontes variadas e a 
crítica interna e externa à documentação (BACELLAR, 2010) são pontos básicos que devem ser tomados em conta para uma pesquisa dessa natureza. Além disso, a pesquisa aqui apresentada dialoga com os procedimentos da história econômica, procurando a relação constante entre a história e a teoria econômica (CARDOSO e BRIGNOLI, 1983; BARROS, 2012; BARBOSA, 2009; TORTELLA, 1986).

Os dados econômicos, muitas vezes, têm origem em notas do Diário Oficial, publicadas pelos clubes, que revelam apenas os dados que os dirigentes estavam dispostos a mostrar. No entanto, como se tratam de dados oficiais publicados em órgãos de divulgação do Estado (como no caso do Diário Oficial) ou de grande circulação (como nos jornais e nas revistas da grande imprensa) podem dar uma boa ideia da dimensão econômica que estes espetáculos passaram a ter a partir da segunda metade do século XIX.

Além dos relatórios e atas de assembleias publicadas no Diário Oficial, há ainda a utilização de publicações anuais do Derby Club, conhecidos como "Anuário Sportivo". São publicações oficiais de um dos clubes mais importantes do período e que tem o potencial de mostrar os dados econômicos e outras atividades que o clube fazia questão de publicitar. Tanto os dados provenientes do Diário Oficial, quanto dos anuários esportivos, dão credibilidade aos dados, uma vez que são oficiais. No entanto, estas fontes de dados também têm suas limitações, uma vez que estão restritas àquilo que os gestores das organizações acreditavam ser necessário e possível publicitar.

Outra fonte de dados vem da imprensa periódica carioca. Weber (2001, p. 188) apontava as potencialidades de uma sociologia da imprensa, tendo em conta o fato de que "a imprensa é necessariamente uma empresa capitalista e privada" e que, portanto, tem uma demanda crescente de capital. Percebemos a constante divulgação de notícias, corridas, resultados e palpites para apostas como uma necessidade editorial de aumento de vendas. No entanto, este tipo de material, se analisado a partir desta perspectiva, pode revelar o aumento da importância social de nosso objeto de estudo. Além disso, contem informações valiosas que se perderam com o tempo a respeito de clubes já inexistentes e suas corridas.

Para esta pesquisa, os periódicos foram utilizados para verificar a participação dos clubes de corridas cariocas no mercado de entretenimento da cidade. Além disso, serviram para mostrar os valores movimentados em clubes menores e para confrontar com as informações consideradas "oficiais" publicadas no Diário Oficial ou nas edições de anuários do Derby Club. Os periódicos podem descortinar uma série de fenômenos relacionados ao turfe.

\section{O turfe no Brasil: organização de um grande negócio}

Um dos aspectos menos estudados no Brasil foi a gestação, em meados do século XIX, do mercado de atividades de entretenimento nas grandes capitais do país. Já não são poucos os estudos sobre esporte com abordagens da história social, cultural e até mesmo de história comparada (MELO et al., 2013). No entanto, ainda carecemos de trabalhos com foco nos estudos dos aspectos econômicos da história da organização dessas atividades, das organizações responsáveis pela produção dos eventos e da própria 
existência do turfe como um campo e da formação e crescimento de um mercado consumidor para estes novos fenômenos.

Sobre o turfe, atividade esportiva que primeiro se estruturou no país e com fortes componentes econômicos envolvidos, pouco ou nada se conhece sobre as características econômicas de seu desenvolvimento. Existem bons estudos sobre o turfe carioca a partir da perspectiva, principalmente, da história cultural, como os já realizados por Melo (2001). Apesar do foco da análise recair nos aspectos culturais desse fenômeno, o autor não deixou de perceber importantes características econômicas desta atividade. De suas pesquisas, podemos nos aprofundar um pouco em um universo de prêmios, apostas, trabalho, investimento do Estado, construção de estádios, relação dos esportes com os meios de transporte da cidade, entre tantos outros pontos que seriam mais bem apreciados com o auxílio das ferramentas conceituais e metodológicas específicas da história econômica.

O turfe se organizou e expandiu no momento em que a sociedade brasileira passava por uma grande transformação. Tratava-se de um momento de transição entre uma economia e uma sociedade basicamente agrária para outra que passava a conviver com crescimento industrial e urbano, adaptando as possibilidades econômicas e socioculturais a esta nova realidade. Podemos ver as atividades turfísticas como um exemplo dessas novas possibilidades, transformando-se em um dos mais poderosos catalizadores de uma nova ordem social, a "ordem social competitiva", em um período importante da evolução interna do capitalismo (FERNANDES, 2006, p. 243).

$\mathrm{O}$ estreitamento de relações econômicas com a Inglaterra durante todo o século XIX e o aumento significativo de negócios entre os dois países após o fim do tráfico negreiro fez com que muitos dos hábitos sociais e culturais dos britânicos passassem a ser introduzidos no Brasil, e a prática do turfe e a organização de corridas de cavalo para comercialização era um dos hábitos sociais de maior destaque nas grandes cidades inglesas (TRANTER, 1998). As corridas a cavalo, assim como as lutas, as regatas e as corridas a pé, atraíam grandes audiências na Inglaterra desde o século XVII. Passaram a ser organizadas por promotores que buscavam lucrar com tais atividades quando se percebeu seu enorme potencial de geração de receitas com a venda de ingressos. No entanto, o desenvolvimento de indústrias, o crescimento demográfico das cidades e o desenvolvimento de meios de transporte rápidos e eficientes, como o trem, proporcionaram uma rápida expansão de clubes privados que passaram a promover eventos em que se realizavam apostas, mas não eram cobradas entradas até meados da década de 1870 (GUTTMANN, 1985).

De acordo com Guttman (1985), apenas no último quartel do século XIX, os empreendedores perceberam que as pistas fechadas eram maneiras de, simultaneamente, controlar as multidões e arrecadar uma boa soma de dinheiro. De acordo com o autor, tais instâncias de racionalização econômica faziam parte de uma tendência maior de modernização das instituições esportivas, que introduziam aparelhos mais precisos para medir os tempos de corrida dos cavalos e com a burocratização do esporte através de instituições como o Jockey Clube inglês (GUTTMANN, 1985, p.112). O dinheiro que fluía para os cofres dos clubes de corrida advinha das apostas dos espectadores. "A razão básica para esta falta de comercialização do esporte era o baixo poder de compra 
da classe trabalhadora" (VAMPLEW, 1988, p. 43). Tal mudança só se processou a partir do aumento médio nos salários da classe trabalhadora que puderam ser observados nos anos 1880 e 1890 na Grã Bretanha.

No Brasil do século XIX, as práticas inglesas eram vistas como modernas, em detrimento das práticas portuguesas, do antigo colonizador, tidas como arcaicas (Freyre, 1948). Os clubes de corrida surgidos no século XIX no Brasil podem ser pensados a partir dessa perspectiva. Os próprios nomes dos clubes de corridas mais importantes da cidade mostram a necessidade de uma associação com as práticas inglesas: Derby Club e Jockey Club.

Para a organização de um clube, havia a necessidade de investimento de capital considerável para que se adquirisse um grande terreno capaz de suportar a pista de corridas, as arquibancadas e demais espaços destinados ao público presente (banheiros, casas de apostas), aos atletas (vestiários, entradas especiais) e aos cavalos (baias para os animais, locais para beber água, depositar os excrementos, guardar equipamentos). Para conseguir formar o monopólio da produção de eventos turfísticos comercializáveis, segundo as acepções de Karl Marx, as empresas (neste caso os clubes de corrida) deveriam aumentar o investimento no capital constante (estádio/sede/animais/uniformes/marcadores de tempo) e fazer crescer a parte fixa do capital constante (estádio e sede).

Para viabilizar tais investimentos, podemos identificar a solicitação, a presença e a valorização de membros da alta direção do governo nas corridas de cavalos. Tal envolvimento era considerado pelos organizadores como uma dimensão fundamental para legitimar o turfe, pois difundia a representação de que era uma prática adequada e respeitada. Além disso, facilitava o contato no sentido de solicitação de auxílios financeiros para a manutenção das corridas.

A presença das principais autoridades do país pode ser observada desde a primeira corrida oficial do país, em 1847, que teve a presença inclusive de D. Pedro II, imperador do Brasil (MELO, 2001). Aliás, Sua Majestade era presença constante nas principais provas esportivas do Rio de Janeiro e de Niterói, como atestam as propagandas em alguns periódicos de provas de regatas. Um exemplo pode ser visto em 1885, nas páginas do jornal "O Paiz", que publicitava a Grande Regata do Club de Regatas Guanabarense "com a assistência de Suas Majestades e Altezas Imperiais" (O PAIZ, 1885, p.5).

O primeiro grande clube de corridas do Brasil foi a Sociedade Jockey Club. Fundado em 1868, com o intuito de organizar corridas de cavalo e comercializá-las ao público através da venda de ingressos e da possibilidade de apostas nas corridas, o sucesso do empreendimento logo estimulou a formação de novos clubes de corrida com o mesmo intuito. Prado Junior (1963, p. 86) apontava que com o fim do tráfico negreiro em 1850, "os capitais que eram empregados nestas ilícitas transações afluíram à praça", a vida comercial se intensificou, as emissões bancárias cresceram e "esta intensa atividade se manifesta nos primeiros grandes empreendimentos materiais do país, todos posteriores a 1850". O autor aponta como exemplos desses grandes empreendimentos materiais o telégrafo, inaugurado em 1852, a primeira estrada de ferro, inaugurada em 1854, a construção da Estrada de Ferro D. Pedro II, que teve início em 1856. Segundo o 
Prado Junior (1963, p. 86), “assinala-se, portanto, este período que se inaugura com a segunda metade do século passado, pelos primeiros passos no sentido da modernização do país". Santos (2010), mostra que na virada do século XIX para o século XX, as atividades agrícolas e pecuaristas no Rio de Janeiro, enfrentaram crises frequentes e apontaram também para a diversificação de atividades, principalmente voltadas para iniciativas industriais.

A segunda metade do século XIX seria marcada, portanto, por uma diversificação de investimentos, fruto do capital disponibilizado pelo quase encerramento das atividades já ilegais do comércio de africanos para o Brasil. Como apontou Pinto (1978, p. 137-138), “com a cessação brusca do tráfico [...] o capital nele invertido encontrou-se subitamente em disponibilidade. E o que se segue é uma diversificação na sua aplicação ativando vários setores da vida nacional". Pode-se, portanto, entender os investimentos nos clubes de corridas, com um desses vários setores que passaram a ser ativados.

As relações da Sociedade Jockey Club com figuras importantes do Estado vinham desde seus primórdios. Um dos aspectos em que esta pesquisa procura lançar luzes e justamente sobre o processo que desencadeou a monopolização do mercado de corridas de cavalo no Rio de Janeiro. Se no início podemos perceber a presença de inúmeros clubes oferecendo corridas e possibilidades de aposta, na primeira metade do século XX, só o Jockey Club e o Derby Club existiam. Mesmo assim, acabaram por se fundir em uma única agremiação de nome Jockey Club Brasileiro.

A formação de monopólios, segundo Marx, envolve dois aspectos principais: o aumento do investimento no capital constante (estádio/ sede/ animais/ uniformes/ marcadores de tempo, prêmios em dinheiro, etc.); e o crescimento da parte fixa do capital constante (estádio e sede). O Jockey e o Derby foram dois pilares deste processo, sempre investindo em prêmios altíssimos que atraíam os proprietários dos melhores cavalos, ou na infraestrutura do clube, como as arquibancadas, as casas de vendas de apostas (as poules), relógios para marcação de tempo e outros equipamentos.

Na Inglaterra, por volta da década de 1860, Vamplew (1988) e Guttmann (1998) consideram que a classe trabalhadora não tinha poder de compra suficiente para sustentar um calendário regular de produção de eventos esportivos comercializáveis. Se este era o quadro no país mais desenvolvido em termos econômicos do mundo, podemos fazer ideia de como seria complicada a formação de um mercado consumidor para este tipo de evento no Brasil a partir da segunda metade do século XIX. Vale lembrar que o país manteve a escravidão como instituição legal até 1888, impedido, $a$ priori, a possibilidade dessa parcela da população de se tornar consumidora de espetáculos esportivos pagos. Em 1872, no Rio de Janeiro, os escravos somavam quase 20\% da população: 48.239 escravos de um total de 274.972 habitantes (DIRETORIA GERAL DE ESTATÍSTICA, RECENSEAMENTO GERAL DO IMPÉRIO DE 1872, 1876, p. 875).

Alguns dos principais clubes de corridas de cavalo surgiram ainda no período escravocrata. Muitos dos donos de cavalos eram também membros da elite agrária carioca, portanto detentora de escravos. Porém, o crescimento econômico, industrial e urbano nas principais cidades do Brasil, como São Paulo e Rio de Janeiro era notório. 
Os dados populacionais dos censos da cidade do Rio de Janeiro de 1872 e 1890 elucidam o crescimento da população do município no período. Em 1890, a cidade tinha já 522.651, um crescimento da ordem dos $100 \%$ desde o último censo, realizado 18 anos antes (BRASIL, 1895, p. 235).

No entanto, para além da venda de ingressos, outro sistema de consumo das corridas de cavalo era o sistema de apostas. Tal serviço destinava-se a um público disposto a pagar mais do que simplesmente as entradas para assistir às corridas. Os organizadores das corridas ofereciam prêmios em dinheiro para aqueles que apostassem e acertassem os cavalos que venceriam a corrida, além de inúmeras outras possibilidades de combinações com segundos, terceiros, quarto lugares. Cada corrida tinha prêmios diferenciados e haviam os chamados "Grande Prêmios", corridas especiais com altíssimas quantias em dinheiro sendo oferecidas aos vencedores das apostas.

A análise das apostas nos pode revelar dois aspectos relevantes da organização destes eventos como ações de comercialização de serviços de entretenimento e de impulsão a uma mentalidade capitalista. Ajuda a entender o empreendimento enquanto negócio, assim como possibilita a percepção da aposta como possibilidade para se ganhar dinheiro por parte daqueles que pagavam para tentar adivinhar o cavalo vencedor. Vejamos apenas um exemplo. De acordo com o "Annuario da Estação Sportiva de 1887", publicado pelo Derby Club, este clube realizou de 17 eventos naquele ano. No primeiro deles, com oito páreos, realizado no dia $1^{\circ}$ de maio, o clube pagou um total de 8:610\$000 em prêmios e teve uma movimentação de apostas de 130:900\$000 (VALLADÃO, 1917, p. 158). Tais números nos mostram o quão alto podiam ser os valores envolvidos no mercado de apostas e ajudam a compreender como eram reais e animadores os investimentos neste tipo de empreendimento.

Os dados resumidos do final de 1887 são bastante esclarecedores quanto à possibilidade de rentabilidade do negócio das corridas de cavalo no Derby. No ano de 1887, o clube organizou 17 eventos, com 117 páreos e pagou um total de 171:225\$000 em prêmios. Tais despesas foram pagas com apenas um dos 17 eventos: o Grand Premio Rio de Janeiro, realizado em dois de outubro, que recebeu movimentação das apostas de 255:920\$000. Só naquele ano, o total arrecadado com apostas pelo clube foi de 2.489:748\$000, quase 15 vezes mais do que aquilo que foi gasto com prêmios (VALLADÃO, 1917, p. 158).

$\mathrm{Na}$ outra ponta do negócio, se os prêmios não chegavam perto daquilo que os clubes auferiam como empreendedores, os valores a serem recebidos pelos apostadores vencedores tornava-se um grande atrativo em uma cidade de baixos salários e poucas oportunidades para os menos abastados. No Grande Prêmio Rio de Janeiro, as apostas para o primeiro lugar custavam $1 \$ 000$. Havia prêmios para o primeiro, segundo e terceiro lugares. As corridas mais importantes do dia, a $4^{a}$ (com cavalos de qualquer país) e a $5^{\mathrm{a}}$ (com cavalos brasileiros), pois pagavam os maiores prêmios e por isso atraíam maior número de apostadores: 1:000\$000 para quem acertasse o primeiro lugar, $250 \$ 000$ caso o cavalo apostado ficasse em segundo e $150 \$ 000$ no caso da terceira colocação a serem divididos entre os acertadores. 
A quarta corrida foi a mais movimentada, contando com os $1 \$ 000$ de 2.133 apostadores, o que gerou um total de apostas de 21:330\$000. Cada poule comprada para a égua vencedora, Diva, rendeu $43 \$ 200$ aos apostadores vencedores. Muita tentação para aqueles que adoravam jogar. Oito páreos, cada páreo contando com dez a doze cavalos, apostas a partir de $1 \$ 000$, possibilidade de voltar para casa com 100, $150 \mathrm{mil}$ réis, gastando quatro ou cinco mil, em apenas um dia.

O número de apostadores nas corridas impressionava. Em qualquer evento daquele ano, em qualquer páreo, raramente o número de apostas ficava abaixo dos mil. $\mathrm{Na}$ maioria das vezes, de 1300 a 1500 apostadores por páreo disputavam os prêmios gerais que variavam de $500 \$ 000$ a $800 \$ 000$. As principais corridas do dia ofereciam prêmios de 1:000\$000 e o número de apostadores sempre ultrapassava os dois mil. A corrida que despertou maior interesse nos apostadores cariocas no ano de 1887, foi a do Grande Prêmio Rio de Janeiro, citado anteriormente. O quinto páreo, que ofereceu como prêmio 8:000\$000, o maior do ano, além de uma obra de arte, atraiu o impressionante número de 8.554 apostadores (VALLADÃO, 1917, p 119 a 129).

No final do século XIX, apesar de o Derby Club e o Jockey Club serem os clubes que mais movimentavam dinheiros nas apostas, clubes como o Villa Izabel não ficavam muito distantes quando o assunto era movimentação de apostas. Como vimos anteriormente, uma "poule" no Derby Club gerava em torno de 20:000\$000. De acordo com a publicação especializada "almanak Sportiva", as "poules" chegavam a movimentar pouco mais de 16:000\$000.

\section{O caminho para o monopólio}

Num primeiro momento, há um número razoável de clubes que atraem capitais e investimentos. Segundo Melo (2001), na década de 1880, o Rio de Janeiro chegou a contar com cinco clubes de corrida. Os mais famosos eram o Jockey Club e o Derby Club, mas clubes como o Prado Villa Izabel, o Derby Fluminense e o Prado Guarani buscavam também um espaço na disputa pelo mercado de espectadores e apostadores em eventos esportivos. De acordo com o Almanak Gazeta de Notícias, de 1889 (p.76), a cidade do Rio de Janeiro contava com quatro clubes de corridas: Jockey Club, o Derby Club o Prado Villa Izabel e o Sport Club. Interessante notar que três destes clubes estavam localizados na mesma região da cidade, no bairro de São Cristovão (Jockey, Derby e Sport Club) e apenas um deles ficava em outro bairro, na Villa Izabel. Além destes quatro clubes da cidade, a vizinha Niterói também contava com um clube de corridas, o Prado Guanabara.

Ainda nos primeiros anos do século XX, era possível ver nas páginas de grandes periódicos cariocas a presença de clubes de corridas menores que competiam no mercado de corridas contra os grandes clubes como o Jockey e o Derby. No jornal "O Imparcial", há a notícias de corridas no "Clube de Corridas Santa Cruz" (O IMPARCIAL, 27/12/1912, p. 7), clube localizado nos subúrbios da cidade do Rio de Janeiro.

O fato do Derby e do Jockey serem os clubes que mais conseguiam investimentos pode ser visto como parte da etapa de concentração de capital no 
processo de formação de monopólio: os dois clubes acumularam capital individualmente, de forma a aumentar a quantidade de capital controlada por cada um isoladamente. $\mathrm{O}$ crescente mercado de corridas de cavalo explica o crescente aumento da produção e a tendência no sentido da eliminação da concorrência.

Esta etapa seria seguida de outra, a fase de centralização do capital, que pode ocorrer através de dois agentes: a concorrência e o acesso ao crédito. A concorrência é o período em que capitalistas maiores derrotam os menores e "parte dos capitais menores desaparece, outra parte passa às mãos das empresas mais eficientes, que dessa forma aumentam de tamanho" (SWEEZY, 1986, p. 198). Aqui poderíamos ver as inúmeras tentativas de clubes menores de concorrerem com outros e deixando de existir, como o caso do Club Villa Izabel.

Se o Prado Villa Izabel conseguia que a Cia. Villa Izabel, empresa privada de bondes do Rio de Janeiro, disponibilizasse bondes extraordinários que levavam os espectadores e apostadores até o clube (O PAIZ, 1885, p.7), o Jockey e o Derby tinham um parceiro mais estratégico. Um dos mecanismos utilizados pelos dirigentes dos dois principais clubes de corridas da cidade foi o estabelecimento de parcerias com a Estrada de Ferro D. Pedro II, posteriormente renomeada para Central do Brasil, de propriedade do Estado. Esta empresa oferecia trens especiais para as corridas, com veículos indo direto da Estação Central do Brasil até a estação Derby Club, ou até a estação Jockey Club. Os dois clubes, que detinham fatia importante do mercado de espetáculos turfísticos não realizavam provas nos mesmos dias, para que as corridas dos dois clubes não concorressem. Os trens eram anunciados no Diário Oficial, veículo oficial do governo brasileiro.

Para conhecimento do público, declara-se que, domingo, 5 do corrente [outubro de 1890], por ocasião das corridas do Prado Fluminense, haverá trens especiaes directos para conducção de passageiros, desde ás 10 horas da manhã até a 1 hora e 30 minutos da tarde e depois de concluídas as corridas. Os trens especiaes não pararão nas estações $\mathbf{S}$. Diogo, S. Christovão e Madureira. O preço da passagem de ida e volta, sem distinção de classe, é de \$500 (BRASIL, 1890, p. 4.434)

O segundo agente da concentração seria o acesso ao sistema de crédito, que "logo se tornou uma nova e formidável arma na luta pela concorrência e se transforma num mecanismo social imenso para a centralização de capitais" (MARX, 1867/1974, p. 687). Podemos então averiguar como se deu esse processo de acesso ao crédito por parte dos grandes clubes de turfe, na tentativa de entender como tais agremiações tiveram acesso às mais variadas possibilidades de crédito, além de benesses governamentais, frente a outros pequenos, que lhes deram vantagem na obtenção de capital.

As ligações dos membros desses dois clubes com o Estado brasileiro fez com que os mesmos concentrassem as atenções das autoridades e, obviamente, algumas facilidades só alcançadas para quem tem relacionamento íntimo com figuras de grande poder. Destacamos aqui apenas um exemplo sobre o Jockey Club. Este clube realizou, a partir de 1893, exposições anuais de raças cavalares nacionais. De acordo com o relatório do enviado do governo, José Joaquim de Negreiros Sayão Lobato, o 
representante do Ministro de Estado e dos Negócios Interiores, General Bibiano Fontoura, que acompanhou a segunda edição, a pouca concorrência de animais se devia a dois fatores, ambos econômicos. O primeiro, a falta de prêmios em dinheiro para os primeiros colocados e o segundo, a dificuldade e os elevados custos com de locomoção dos animais por meios de transporte. Nas palavras de Sayão Lobato, para além das medalhas de ouro, prata e bronze ao melhor cavalo, à melhor égua e melhor potro, faltavam prêmios em dinheiro "que atraísse os proprietários de animais pelo incentivo do lucro, compensando de alguma sorte muitas despesas e mesmo perigos que há na viagem de animais" (BRASIL, 1894, p. 676).

O representante do governo elogiava a atitude do Jockey Club e fazia um pedido ao governo: "Parece-me que o governo poderia animar taes exposições concedendo condução gratuita nas vias de transporte fluviais e terrestres do Estado, ou por ele subvencionadas ou garantidas, e concedendo um prêmio pecuniário ao melhor produto de puro sangue". Afirmava ainda que tais "favores" seriam limitados às exposições e não poderiam das lufar a "abusos, nem a grandes despesas para os cofres públicos". Justificava a necessidade de atenção especial para a necessidade do governo contribuir para o desenvolvimento de uma "indústria a que o governo não pode ser indiferente" (BRASIL, 1894, p. 676).

Dois anos depois, o mesmo José Joaquim de Negreiros Sayão Lobato, novamente designado para representar o governo na IV Exposição Nacional do Jockey Club, como jurado dos concursos, insistia na mesma questão. Reafirmava as dificuldades e custos de transporte de animais caríssimos como grande impedidor de uma maior popularidade do evento. E clamava novamente para o que já havia afirmado no relatório de dois anos antes: a necessidade do governo em ajudar o evento com transporte gratuito aos expositores nas vias férreas e fluviais públicas e concedendo prêmios em dinheiro aos vencedores (BRASIL, 1896, p. 2.619-2.620).

Apenas em 1898, o governo autorizou a formação da Sociedade Animação da Indústria Pastoril, que passaria a ser responsável pela organização das exposições anuais das raças nacionais cavalares, bovinas, muares e suínas. Os prêmios passariam a ser pagos em dinheiro para os primeiros e segundos colocados de cada espécie, divididos em categorias de macho, fêmea e filhote. O dinheiro para o pagamento dos prêmios viria da criação de um novo imposto sobre o valor de cada bilhete de aposta que se fizesse nas casas de poules das sociedades de corridas, frontões, velódromos, jardins zoológicos e outros estabelecimentos congêneres. As sociedades de corrida "de forma recreativa" pagavam $1 \%$ do valor de cada bilhete como imposto. Já as "sociedades anônimas", caso dos grandes clubes de corridas como o Jockey e o Derby, pagavam imposto de $2 \%$. As demais sociedades e empresas, 3\%. Do dinheiro arrecadado, um terço deveria ser destinado ao pagamento dos prêmios da Exposição Anual. O outro terço deveria ser usado para custeio da escola de veterinária e o outro para a criação de uma escola de equitação (BRASIL, 1898, p. 9-10).

Na VIII Exposição, realizada em 1900, a lista de jurados do evento contava com figuras de destaque do governo e do esporte. Dentre elas, estavam o prefeito do Distrito Federal, Antonio Coelho Rodrigues, além de representantes do Jóquei Club, do Rio de Janeiro e de São Paulo, e do Derby Club carioca (BRASIL, 100, p. 3.490). A presença 
dessas figuras atestava a crescente importância que o evento ia ganhando com o passar dos anos.

O apoio que clubes como o Jockey Club, tanto o paulista, quanto o carioca, recebiam do Estado chagava mesmo a incomodar figuras antigas e tradicionais da política brasileira. Na votação da lei orçamentária do Estado de São Paulo, o senador Ezequiel Ramos, propunha a supressão da verba de 10:000\$000 (dez contos de réis) destinada ao Jockey Club de São Paulo. Tais despesas, em sua visão, só atendiam "a satisfação de necessidades privadas". O senador argumentava que o serviço a que o clube de corridas se dizia prestar (melhorar a raça cavalar brasileira) não vinha sendo realizado. O clube havia se transformado

em um jogo esportivo de venda de poules onde os potentados, os poderosos da terra vão frequentemente satisfazer os seus legítimos desejos quanto a corridas de cavalo. [...] Quando estamos fazendo rigoroso esforço para equilibrar o orçamento, quando chegamos a tirar da Biblioteca Pública as verbas necessárias para manter-se, vai o Estado contribuir para a sociedade do Jockey Club?! (SÃO PAULO, 1898, p. 25.292).

Mesmo não sendo unanimidade entre políticos cariocas e paulistas, os clubes de corrida conseguiram apoio governamental para que pudessem conquistar e monopolizar seus mercados. Vimos apenas um exemplo do Jockey Club do Rio de Janeiro que, através da presença de figuras importantes da sociedade carioca, conseguiu atrair os investimentos do governo por ser o legitimador das raças cavalares e bovinas no Brasil. Anos depois, em 1911, o governo autorizou o Jockey Club a levantar um empréstimo de 400:000\$000 para a construção de um prédio na Avenida Central que funcionaria como uma das sedes do clube. Segundo dados fornecidos pelo clube, a garantia do empréstimo seria a hipoteca de todos os bens da instituição: o prado, as arquibancadas e demais dependências do clube de corridas, na Rua São Francisco Xavier, um terreno de cocheiras na Rua Major Suckow e o terreno em que seria levantado na Avenida Central. Todos os bens juntos somavam a quantia de 720:000\$000. Os dirigentes afirmavam que tal prerrogativa poderia ser dada ao clube, pois o mesmo tinha por finalidade "o melhoramento da raça cavalar" (BRASIL, 1911, p. 4.392).

Essa foi uma das muitas estratégias do Jockey Club, que posteriormente se fundiria ao Derby Club, formando o Jockey Club Brasileiro e consolidando a monopolização da produção dos espetáculos turfísticos na cidade. Quando se fazem consultas nos periódicos cariocas a partir dos primeiros anos do século XX, não existem mais notícias sobre prados como o de Villa Izabel, ou o Prado Guarani. As notas se resumem a falar sobre o Derby Club e o Jockey Club. O primeiro número da revista "Estação Esportiva", assim como os números subsequentes daquele ano (1911), não fazem referência aos outros clubes da cidade. No periódico "Rio Sportivo", publicado a partir de 1909, também não se encontram nem notícias, nem publicidade de outros clubes de corridas de cavalo que não sejam do Jockey Club e do Derby Club.

Foi neste período que se deram as condições da fase final do desenvolvimento do capitalismo monopolista na produção dos espetáculos de turfe no Rio de Janeiro. A concorrência entre Jockey e Derby se exacerbou até a fusão das duas agremiações, 
sendo essa característica básica desta fase: "A concorrência tende a se transformar numa luta mortal que não beneficia ninguém. Quando isso ocorre, o terreno para o movimento de combinação está preparado" (SWEEZY, 1986, p. 54).

\section{Considerações finais}

O presente trabalho é apenas um ensaio inicial sobre algumas ponderações feitas a respeito da primeira modalidade de empreendimento esportivo comercializável do país. A primeira impressão é que o processo de monopolização deste setor da economia do entretenimento parece corresponder aos aspectos mais gerais da análise marxista deste fenômeno. A movimentação no sentido da concentração e centralização do capital até a fusão dos dois maiores clubes da cidade, o Jockey Club e o Derby Club, formando um clube de corridas que monopolizou a produção e distribuição de corridas de cavalo na cidade do Rio de Janeiro parece acompanhar as observações de Marx sobre o processo mais geral da etapa monopolista do capitalismo.

Ao observarmos o turfe brasileiro em seus primórdios como um campo organizacional, podemos perceber a existência e o funcionamento dos diversos agentes envolvidos na produção dos espetáculos de entretenimento. $\mathrm{O}$ conceito nos ajuda a identificar as interações entre os agentes e as organizações e as estratégias para a disputa de poder e para a monopolização da produção deste atrativo entretenimento do período. Em nosso caso, as organizações esportivas formadas por elementos da elite carioca conseguiram se aliar ao Estado para a obtenção de benesses tanto fiscais, quanto de facilitação de acesso ao público e de publicidade de seus eventos.

Ao se posicionar como um prestador de serviços ao país, como no exemplo das exposições de raças cavalares, a Sociedade Jockey Club foi conseguindo ser caracterizada pelo governo como uma organização que precisava da ajuda do Estado. A persistência de seus gestores em organizar as exposições mesmo sem o apoio financeiro do Estado e a habilidade estratégica dos mesmos em continuar convidando representantes do governo tanto para a exposição, quanto para serem julgadores das raças, foi recompensado anos depois. O governo decidiu por criar um novo imposto direcionado com valores destinados para a organização da exposição. Aqui podemos notar como as relações de poder destas organizações foram historicamente estabelecidas, conferindo vantagens a alguns e desvantagens para outros.

A análise deste esporte como oferta de consumo no mercado de entretenimento traz uma outra acepção sobre a observação a ser feita para este tipo de serviço, quando se refere ao esporte: as apostas. A par da possibilidade de assistir ao espetáculo, os consumidores poderiam participar mais ativamente das movimentações econômicas do clube despejando milhares contos de réis nas poules de apostas. Este seria um dos mecanismos que fizeram do turfe, durante tempos, o esporte mais popular, mais divulgado pela imprensa e que atraía as maiores multidões a eventos de entretenimento.

A investigação de aspectos históricos da gestão do esporte no Brasil ainda tem muito para crescer. Os conceitos aqui utilizados não oferecem as chaves definitivas para a resolução dos problemas. Ainda precisam ser investigados muitos aspectos deste tema, mesmo dentro das corridas de cavalos. É necessário que as pesquisas avancem com a 
possibilidade de dialogar mais amplamente com procedimentos metodológicos e questões de pesquisa de outros campos do conhecimento.

A análise aqui realizada teve por objetivo analisar a formação de um monopólio na produção de corridas em que aspectos importantes deixaram de ser analisados. Caminhos para pesquisas futuras podem analisar não só o processo de monopolização existente na produção e comercialização de ouros espetáculos esportivos, mas também analisar outras vertentes do processo, baseado em alternativas de interpretação àquela aqui apresentada. Um dos exemplos pode ser a análise de como se deu a formação da identidade organizacional da Sociedade Jockey Club como um clube que colaborava para a melhoria da economia do país e quais as vantagens advindas deste processo.

No caso do esporte brasileiro, é notório que o desenvolvimento de práticas de gestão ao longo da história se solidificaram no interior das organizações. Compreender o contexto em que essas práticas se concretizaram auxiliará na compreensão da gestão do esporte no país. E pode ainda fornecer subsídios para a compreensão da cultura organizacional das organizações esportivas brasileiras.

\section{Referências}

ALMANAK DA GAZETA DE NOTÍCIAS PARA 1889. Rio de Janeiro: Typographia da Gazeta de Notícias, 1889.

ARNOULD, Erci.; THOMPSON, Craig. Consumer Culture Theory (CCT): 20 years of research. Journal of Consumer Research, v.31, n.4, p. 868-889, 2005.

BACELLAR, Carlos. Uso e mau uso dos arquivos. In: Pinsky, Carla (org.). Fontes históricas. São Paulo: Contexto, 2005, p. 23-72.

BAKKER, Gerben. Entertainment Industrialized: the emergence of the international film industry, 1890-1940. Enterprise \& Society, v. 4, p. 1467-2227, 2003.

BARBOSA, Wilson. O Lugar da História Econômica entre as Ciências Sociais. Revista de Economia Política e História Econômica, v. 18, n.1, p. 125-173, 2009.

BARROS, José D’Assunção. Os sistemas econômicos e suas formas de racionalidades: a busca das singularidades na moderna história econômica e seus novos desafios.

Revista de Economia, v. 38, p. 109-131, 2002.

BOOTH, Charles.; ROWLINSON, Michael. Management and Organizational History: Prospects. Management \& Organizational History. v.1, n.1, p. 5-30, 2006.

BOUCHER, Robert. Toward achieving a focal point for sport management: A binocular perspective. Journal of Sport Management, v. 12, n.1, p. 76-85, 1998.

BOURDIEU, Pierre. Questões de Sociologia. Lisboa: Fim de Século, 1984. . The Social Space and the Genesis of Groups. Theory and Society. v. 14, n. 6, p. 723-744, 1985. 
BRASIL. Diretoria Geral de Estatística, Recenseamento Geral do Império de 1872. Rio de Janeiro, DF: Typ. Leuzinger / Tip. Commercial, 1876, 12 volumes.

BRASIL. Recenseamento geral da Republica dos Estados Unidos do Brazil em 31 de dezembro de 1890. Rio de Janeiro, DF, Directoria Geral de Estatística, 1895.

BRASIL. Ministério dos Transportes. Diário Oficial dos Estados Unidos do Brasil, Poder Executivo, Rio de Janeiro, DF, 4 out. 1890, p. 4.434.

BRASIL. Diretoria Geral da Indústria / Indústria Pastoril. Diário Oficial dos Estados Unidos do Brasil. Poder Executivo, Rio de Janeiro, DF, 22 mai. 1894, p. 676.

BRASIL. Diretoria Geral da Indústria / Indústria Pastoril. Diário Oficial dos Estados Unidos do Brasil. Poder Executivo, Rio de Janeiro, DF, 9 jun. 1896, p. 2.619-2.620.

BRASIL. Intendência Municipal. Diário Oficial dos Estados Unidos do Brasil, Atos do Poder Executivo. Rio de Janeiro, DF, 1 jan. 1898, p. 9-10.

BRASIL. Diretoria Geral da Indústria. Diário Oficial dos Estados Unidos do Brasil, Atos do Poder Executivo. Rio de Janeiro, DF, 11 ago. 1900, p 3.490.

BRASIL. Sociedade Jockey Club. Diário Oficial dos Estados Unidos do Brasil. Informes. Rio de Janeiro, DF, 15 abr. 1911, p. 4.392.

BRYANT, Drake. To What Extend did Sport in Late Nineteenth and Early Twentieth Century Britain Become More of a Business and Less of a Sport? NASSH Bulletin, n.3, p. 2-14, april/may, 1986.

CHELLADURAI, Packianathan. Sport management: Opportunities and obstacles. Journal of Sport Management, v. 6, n. 3, p. 215-219, 1992.

DIMAGGIO, Paul; POWELL, Walter. The iron cage revisited: Institutional isomorphism and collective rationality in organizational fields. American Sociological Review, n. 48, p. 147-60, 1983.

FERNANDES, Florestan. A Revolução Burguesa no Brasil. São Paulo: Globo, 2006.

FRISBY, Wendy. The Good, The Bad and The Ugly: Critical Sport Management Research. Journal of Sport Management. n. 19, p. 1-12, 2012.

GUTTMAN, Allen. English Sports Spectators: The Restoration to the Early Nineteenth Century. Journal of Sport History. 1998, v. 18, n.1, p. 55-75, 1985.

HARDY, Stephen. Entrepreneurs, Organizations, and the Sport Marketplace: Subjects in Search of Historians. Journal of Sport History, v. 13, n. 1, pp. 14-33, 1986.

MAANEN, John. Reclaiming Qualitative Methods for Organizational Research: a Preface. Administrative Science Quarterly. v. 24, n. 4, p. 520-526, 1979. 
MARX, Karl. O Capital. Coimbra: Centelha, 1974. $1^{\text {a }}$ ed. 1867.

MCCRACKEN, Grant. Cultura \& Consumo. Rio de Janeiro: Mauad, 2003.

MELO, Vitor. Cidade Sportiva: primórdios do esporte no Rio de Janeiro. Rio de Janeiro: Relume Dumará/Faperj, 2001.

MELO, Vitor, DRUMOND, Maurício, FORTES, Rafael; SANTOS, João. Pesquisa Histórica e História do Esporte. Rio de Janeiro: 7 Letras/Faperj, 2013.

MORGAN, Melissa Johnson; SUMMERS Jane. Marketing Esportivo. São Paulo: Thomson Learning, 2008.

NEALE, Walter. The Peculiar Economics of Professional Sport. Quartertly Journal of Economy. v. 78, n.1, p. 1-14, 1964.

O'BRIEN, Danny; SLACK, Trevor. An analysis of change in an organizational field: The professionalization of English rugby union. Journal of Sport Management, v. 17, p. 417- 448, 2003.

OLAFSON, George. Sport management research: Ordered change. Journal of Sport Management, v. 9, n. 3, p. 338-345, 1995.

PATON, Gary. The future ain't what it used to be. The Dr. Earle F. Zeigler Lecture presented at the annual conference of the North American Society for Sport Management, San Antonio, TX, 1997.

PRADO JR, Caio. Formação do Brasil Contemporâneo: Colônia. $7^{a}$ ed. São Paulo: Brasiliense, 1963.

ROTTENBERG, Simon. The Baseball Player's Labor Market. Journal of Political Economy. n. 64, p. 242-258, 1956.

SÃO PAULO. Votação da Lei Orçamentária do Estado de São Paulo. Diário Oficial Do Estado de São Paulo, Discurso do Senador Ezequiel Ramos, São Paulo, SP, 18 nov. 1898 , p. 25.292.

SANTOS, João. Revolução Vascaína: a profissionalização do futebol e a inserção socioeconômica de negros e portugueses na cidade do Rio de Janeiro (1915-1934) São Paulo. 2010. 489 f. Tese (Doutorado em História) - Faculdade de Filosofia, Letras e Ciências Humanas, Universidade de São Paulo, São Paulo, 2010.

A História Econômica entra em Campo: O Rio de Janeiro e as competições esportivas internacionais de 1919 e 1922 . Revista de Economia Política e História Econômica, v. 27, p. 153-198, 2011.

O Monopólio nos Esportes: uma comparação da organização dos esportes comercializáveis nos Estados Unidos, na Inglaterra e no Brasil (1870-1920). Revista de História Econômica e História das Empresas. v. 15, n 2, p. 47-80, 2012. 
SANTOS, João; MELO, Vitor (Org.). 1922: Celebrações Esportivas do Centenário. Rio de Janeiro: 7 Letras, 2012.

SANTOS, Jorge. Desenvolvimento e Industrialização no Interior do Estado do Rio de Janeiro: uma contribuição para o (raro) debate sobre as peculiaridades regionais.

Revista Economia e Desenvolvimento, n. 22, p. 18-41, 2010.

SLOANE, Peter. The Economics of Professional Football: The Football Club as a Utility Maximizer. Scottish Journal of Political Economy. v. 17, n. 2, p. 121-146, 1971.

SMITH, Ran; LUX, David. Historical Method in Consumer Research: Developing Causal Explanations of Change. Journal of Consumer Research, v. 19, n. 14, p. 595610, 1993.

SWEEZY, Paul M. Teoria do Desenvolvimento Capitalista. Rio de Janeiro: Zahar, 1986.

SZYMANSKI, Stefan. Economists and Sport History. Journal of Sport History, v. 37, n. 1, p. 71-82, 2010.

TRANTER, Neil. Sport, economy and society in Britain 1750-1914. Cambridge: Cambridge University Press, 1998.

TORTELLA, Gabriel. Introduccion a la Economia para Historiadores. Madri: Tecnos, 1986.

TURF. O Paiz, Rio de Janeiro, 8 set. 1885, p. 5 e 7.

TURF. O Imparcial, Rio de Janeiro, 27 set. 1912, p.7.

VALLADÃO, Manoel (Org.) Derby Club: Annuario da Estação Sportiva de 1887. Rio de Janeiro [s.n.], 1917.

VAMPLEW, Wray. The turf: a social and economic history of horseracing. London: Allen Lane, 1976.

. Pay Up and Play the Game: professional sport in Britain (1875-1914). Cambridge: Cambridge University Press, 1988.

VEAL, Aanthony; DARCY, Simon. Research Methods in Sports Studies and Sport Management: a practical guide. Nova Iorque: 2014.

VIDA SPORTIVA. Rio de Janeiro: Imprensa Mont'Alverde, 1889.

VILAR, Pierre. Ouro e moeda na história (1450-1920). Rio de Janeiro: Paz e Terra, 1980.

WEBER, Max. Metodologia das Ciências Sociais. São Paulo: Cortez Editora, 2001. 
ZEIGLER, Earle. Using the rays from history's shining lantern as we face an uncertain future. Journal of Sport Management, v. 6, n. 3, p. 206-214, 1992. 